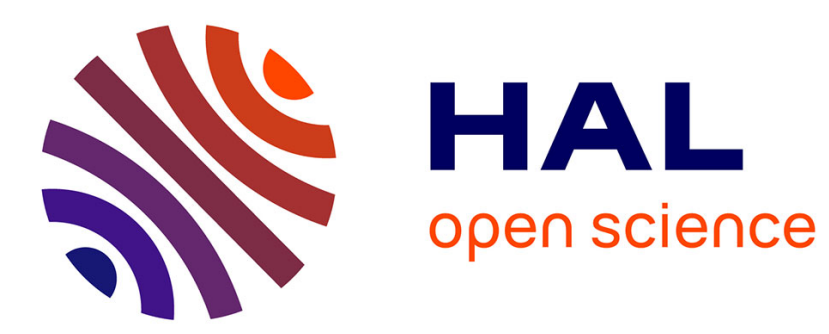

\title{
Optimized sol-gel thermal barrier coatings for long-term cyclic oxidation life
}

\author{
Lisa Pin, Vanessa Vidal, Fabien Blas, Florence Ansart, Sandrine Duluard, \\ Jean-Pierre Bonino, Yannick Le Maoult, Philippe Lours
}

\section{- To cite this version:}

Lisa Pin, Vanessa Vidal, Fabien Blas, Florence Ansart, Sandrine Duluard, et al.. Optimized sol-gel thermal barrier coatings for long-term cyclic oxidation life. Journal of the European Ceramic Society, 2014, vol. 34 ( $\left.\mathrm{n}^{\circ} 4\right)$, pp. 961-974. 10.1016/j.jeurceramsoc.2013.10.013 . hal-01179395

\section{HAL Id: hal-01179395 \\ https://hal.science/hal-01179395}

Submitted on 22 Jul 2015

HAL is a multi-disciplinary open access archive for the deposit and dissemination of scientific research documents, whether they are published or not. The documents may come from teaching and research institutions in France or abroad, or from public or private research centers.
L'archive ouverte pluridisciplinaire HAL, est destinée au dépôt et à la diffusion de documents scientifiques de niveau recherche, publiés ou non, émanant des établissements d'enseignement et de recherche français ou étrangers, des laboratoires publics ou privés. 


\section{OATAO}

\section{Open Archive TOULOUSE Archive Ouverte (OATAO)}

OATAO is an open access repository that collects the work of Toulouse researchers and makes it freely available over the web where possible.

This is an author-deposited version published in : http://oatao.univ-toulouse.fr/ Eprints ID : 14023

To link to this article : DOI:10.1016/j.jeurceramsoc.2013.10.013

URL : http://dx.doi.org/10.1016/j.jeurceramsoc.2013.10.013

\section{To cite this version :}

Pin, Lisa and Vidal, Vanessa and Blas, Fabien and Ansart, Florence and Duluard, Sandrine and Bonino, Jean-Pierre and Le Maoult, Yannick and Lours, Philippe Optimized sol-gel thermal barrier coatings for long-term cyclic oxidation life. (2014) Journal of the European Ceramic Society, vol. 34 (n 4). pp. 961-974. ISSN 09552219

Any correspondence concerning this service should be sent to the repository administrator: staff-oatao@listes-diff.inp-toulouse.fr 


\title{
Optimized sol-gel thermal barrier coatings for long-term cyclic oxidation life
}

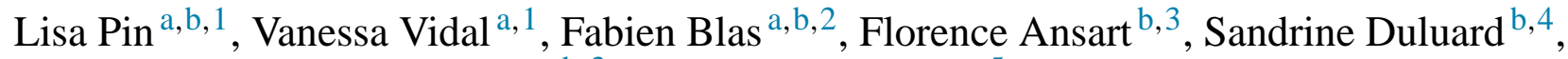 \\ Jean-Pierre Bonino ${ }^{\mathrm{b}, 3}$, Yannick Le Maoult ${ }^{\mathrm{a}, 5}$, Philippe Lours ${ }^{\mathrm{a}, *}$ \\ a Université de Toulouse Mines Albi, Institut Clément Ader, Campus Jarlard, 81013 Albi, France \\ ${ }^{\mathrm{b}}$ Université de Toulouse, UPS-INP-CNRS, Institut Carnot CIRIMAT, 118 Route de Narbonne, 31062 Toulouse Cedex 09, France
}

\begin{abstract}
New promising thermal barrier coatings (TBCs) processed by the sol-gel route are deposited onto NiPtAl bond coated superalloy substrates using the dip and/or spray coating technique. In this study, the optimization of the process, including an appropriate heat treatment prone to densify the yttria-stabilized-zirconia (YSZ) top-coat and leading to the sintering and the development of a resulting crack network, is investigated. In particular, relevant information on internal strain evolution during the heat treatment are obtained using in situ synchrotron X-rays diffraction and confirm a stabilization of the TBC through the occurrence of the micro-cracks that beneficially releases the in-plane sintering stress. Such TBCs are subsequently reinforced using additional material brought within the cracks using sol-gel spray coating. The effect of various process parameters, such as the pre-oxidation of the bond-coat, on the sol gel TBCs consolidation and their cyclic oxidation resistance enhancement, is presented. Reinforced sol-gel TBCs are successfully oxidized up to more than one thousand $1 \mathrm{~h}$-cycles at $1100{ }^{\circ} \mathrm{C}$, without any detrimental spallation.
\end{abstract}

Keywords: Thermal-barrier-coating; Cyclic-oxidation; XRD-synchrotron; Sol-gel-processing; Spallation

\section{Introduction}

Thermal barrier coatings (TBCs) are widely used for various applications in turbojet engine gas turbines and combustion chambers in relation with their excellent thermal protection properties allowing drastic improvement of component durability and efficiency. ${ }^{1,2}$

Typically, the overall thermal protection system includes: (i) the TBC itself, a ceramic top coat (TC) made of yttriastabilized-zirconia (YSZ) acting as thermal insulator, (ii) the superalloy substrate that supports mechanical loading, and (iii)

\footnotetext{
* Corresponding author. Tel.: +33 5634930 78; fax: +33 563493242 .

E-mail addresses: lisa.pin@mines-albi.fr (L.Pin), vanessa.vidal@mines-albi.fr (V. Vidal), fabien.blas@mines-albi.fr (F. Blas), ansart@ chimie.ups-tlse.fr (F. Ansart), duluard@chimie.ups-tlse.fr (S. Duluard), boninojp@chimie.ups-tlse.fr (J.-P. Bonino), yannick.lemaoult@mines-albi.fr (Y. Le Maoult), philippe.lours@mines-albi.fr (P. Lours).
}

an aluminium rich Bond Coat which enhances the cohesion between the substrate and the TBC and develops by oxidation a fine alumina film referred to as the thermally grown oxide (TGO). Within this multi-materials structure, each layer, characterized by specific physical, thermal and mechanical properties, shows - upon processing and "in-service" thermal exposures distinct thermomechanical behaviour, thereby resulting in the establishment of internal thermal stresses. In addition, during high temperature exposure, the alumina $\left(\mathrm{Al}_{2} \mathrm{O}_{3}\right) \mathrm{TGO}$, acting as a diffusion barrier, continuously grows at the interface $\mathrm{BC} / \mathrm{TBC}$ which likely induces local increases of the mismatch between the $\mathrm{BC}$ and $\mathrm{TBC}$ layers.

As a consequence, in highly complex TBC systems, failure mechanisms upon temperature cycling are very intricate and lots of theoretical as well as experimental research investigating mechanistic behaviours and microstructural mechanisms are dedicated to understanding the various processes of crack initiation and propagation, delamination and spallation. ${ }^{2,3}$

Up to now, two main coating processes are used to deposit TBCs for industrial applications, namely the electron beam physical vapor deposition (EB-PVD) and the air plasma spray (APS), each generating specific layer morphology, deposit microstructure and thermo-physical properties. 
EB-PVD results in a columnar structure with grain boundaries roughly normal to the substrate surface allowing satisfactory accommodation of in-service lateral thermomechanical stresses and related strains. However, the thermal conductivity of EB-PVD coatings is not fully optimized as the perpendicular growth of the columns favours extensive heat transfer between the outer surface of the multi-material system and the superalloy substrate. As a comparison, the typical microstructure for APS coating is highly lamellar, resulting in both lower thermal conductivity as the porosity is distributed perpendicular to the heat flux, and lower capability to satisfactorily sustain lateral constraints. Various alternative ways to synthesize TBCs have been proposed in the literature, based on soft chemical processing. ${ }^{4-6}$

In this paper, a new promising method for depositing and reinforcing TBCs, is investigated. Indeed, recently the synthesis and deposition of TBCs using a new attractive sol-gel route has been successfully developed. ${ }^{6-9}$ This versatile technique, promoting, on contrary to EBPVD and APS, non-directional deposition, allows to produce either thin or thick coatings by using dip or spray technique or combined method of both techniques depending on the required result. Sol-gel TBCs show isotropic microstructure with randomly distributed porosities, which straightforwardly results in an interesting compromise between thermal conductivity and mechanical strength. In previous papers, ${ }^{8,9}$ the optimization of the manufacturing process of sol-gel TBCs, the means to enhance their cyclic oxidation resistance using structural reinforcement as well as the mechanisms responsible for their possible damages due to long term cyclic exposure at high temperature have been discussed in detail.

Essentially, the degradation of sol-gel TBCs is initiated by the formation of a regular crack network occurring either during the post-deposition thermal treatment required to sinter the deposit or during the very first cycles of oxidation. It is worth to notice that, in both cases, this regular surface crack network is a result of the in-plane stress release due to the sinter-induced shrinkage of the zirconia scale. Subsequently, under cumulative oxidation cycles, enlargement and coalescence of the cracks occur, promoting the detachment of individual TBC cells and further the complete spallation of the TBC.

To improve the cyclic oxidation resistance of the TBCs, two refinements were proposed both related to the overall processing, namely (i) to enhance the efficiency of the sintering thermal treatment carried outright after TBC deposition and (ii) to stabilize the crack network by filling crack grooves using supplementary dip or spray coating passes. It was shown that the heat treatment parameters such as the heating/cooling rates and the holding time at dwell temperature, dramatically impact the geometrical characteristics of the crack network and consequently their response to cyclic oxidation. After adjustments, the "optimal" thermal treatment parameters, resulting in a significant extent of the TBC life, correspond to an exposure at $1100^{\circ} \mathrm{C}$ during two hours with heating and cooling rates of $50{ }^{\circ} \mathrm{C} / \mathrm{h} .{ }^{8}$

In addition, the feasibility of consolidating sol-gel TBCs by additional fillings of zirconia into the sinter-induced cracks was investigated by adjusting different process parameters such as the choice of either dip-coating or spray-coating and the modification of the slurry viscosity. ${ }^{9}$ It subsequently turned out that spray-coating technique leads to a more efficient and a more homogeneous filling of crack as well as the selection of a specific slurry viscosity for each individual pass depending on the depth and width of crack to fill (by modifying the weight percent of powder). This filling optimization allows salient improvement of the cyclic oxidation behaviour of the spray-coat reinforced TBCs. ${ }^{9}$

Note that the failure mechanisms of the optimized and reinforced sol-gel TBCs are more complex than that of non reinforced TBCs. This results from the more connected microstructure - though more uniform in thickness - of the reinforced TBC showing a composite-like morphology including a skeleton or frame, corresponding to the partially filled cracks, and a matrix, namely the initial sintered YSZ.

The degradation of such TBCs results from the initiation and propagation of cracks, mainly located at the interface between the TBC and the TGO. As a matter of fact, as reinforcement of crack prevails, cracks can extend much more than in nonreinforced TBC before generating spallation, greatly limiting the detachment of individual spalls. Spallation develops following the complete propagation of the crack throughout the whole specimen, producing - when occurring subsequently to a high number of cumulated oxidation cycles - large-scale degradation as observed in EB PVD TBC. Basically, the optimization of both the sintering heat treatment and the procedure for filling the initial crack network, allows a significant improvement of the sol-gel TBC durability during cyclic oxidation at $1100{ }^{\circ} \mathrm{C}$. Typically, sol-gel TBC properly sintered and adequately reinforced can be cycled for $1 \mathrm{~h}$ at $1100^{\circ} \mathrm{C}$ one thousand and five hundred times without spalling which is roughly equivalent to the performance of EB-PVD TBCs.

The present paper proposes to investigate thoroughly (i) the crack network formation due to the initial sintering as well as the effect of the very first oxidation cycles in sol-gel TBCs using synchrotron radiation to monitor "in-situ" the evolution of the thermal strain throughout the $\mathrm{TBC}$ and (ii) the $1100^{\circ} \mathrm{C}$ cyclic oxidation durability of sol gel TBCs for which optimized processing and filling as well as a preliminary oxidation of the bond coat is applied. The overall performances of reinforced sol gel TBCs are compared to previous results and EBPVD TBCs.

\section{Materials and experimental techniques}

\subsection{Processing of the sol-gel TBC}

The various operations conducted to synthesize thermal barrier coatings by the so-called sol-gel route, are presented in details in previous works developed in the laboratory. ${ }^{6,8,9}$ Main steps can be summarized as follows:

i) First step consists in the production of YSZ powders by hydrolysis/condensation (to obtain a gel), supercritic drying and heat treatment at $700^{\circ} \mathrm{C}$ of a precursor YSZ sol $\left(9.7 \%\right.$ mol $\left.\mathrm{YO}_{1.5}\right)$. YSZ aerogel powders crystallize in the tetragonal form. $\mathrm{N}_{2}$ adsorption/desorption analysis of such 

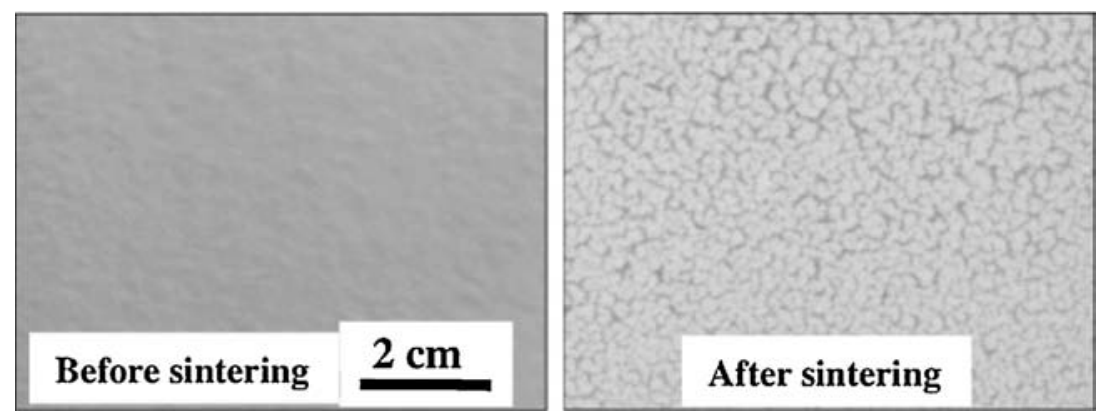

Fig. 1. Optical micrographs of the sol-gel TBC before and after the sintering heat treatment.

powders exhibits a specific surface area $S_{\mathrm{w}}$ of $26 \mathrm{~m}^{2} / \mathrm{g}$. This high $S_{\mathrm{w}}$ is correlated to the small crystallite size $(26 \mathrm{~nm})$ and the alveolar morphology of aerogel YSZ powders. So with such characteristics of the powders, supercritical drying appears as a promising way to prepare stable slurries or loaded sols from fine YSZ particles for TBC applications.

ii) After preparation, nanometric powders, are dispersed into a slurry (ratio of $40 \mathrm{wt} \%$ powder) before shaping on superalloys substrates. Thermal barrier coatings (TBCs) are deposited onto NiPtAl bond coated AM1 superalloy substrates using the dip-coating technique consisting in the immersion of the substrate into the slurry plus withdrawal at a thoroughly controlled rate $(250 \mathrm{~mm}$ per $\mathrm{min})$ to uniformly shape the coatings. Following each dip, the produced layer is dried for $5 \mathrm{~min}$ at $50^{\circ} \mathrm{C}$. This elementary operation is repeated until the required TBC thickness is reached and the deposit of the entire TBC is completed (Fig. 1a). Typically, the thickness of the obtained coatings is in the range $[50 \mu \mathrm{m}$; $150 \mu \mathrm{m}]$.

Finally, processed specimens are sintered $2 \mathrm{~h}$ at $1100^{\circ} \mathrm{C}$ using the appropriate heating and cooling rates discussed above $\left(50^{\circ} \mathrm{C} / \mathrm{h}\right)$ to promote the development of a controlled initial crack network (Fig. 1b). The TBCs consist of tetragonal phase t' yttria-stabilized zirconia (YSZ).

Subsequently, specimens with controlled cracks are reinforced using additional filling of zirconia brought up within crack grooves using spray-coating technique. As detailed elsewhere, ${ }^{9}$ the slurry used for this additional filling process, is composed of the starting sol $(9.7 \mathrm{~mol} \%$ YO1.5) loaded with 10 or $20 \mathrm{wt} . \%$ of a suspension of well-dispersed commercial YSZ powders (TOSOH 8Y) in 1-propanol solvent.

Note that the spray-coating technique allows the control of both the pressure and the displacement rate of the spray nozzle. Between each pass, the coating is dried $5 \mathrm{~min}$ at $50^{\circ} \mathrm{C}$ and finally the specimens are heat treated $2 \mathrm{~h}$ at $1100^{\circ} \mathrm{C}$, using heating and cooling rates of $50^{\circ} \mathrm{C} / \mathrm{h}$.

The most efficient TBC reinforcement is obtained using 2 succesive passes using a sol loaded with $20 \mathrm{wt} \%$ (high viscosity) followed by 4 passes using a sol loaded with $10 \mathrm{wt} \%$ (low viscosity). ${ }^{9}$ Fig. 2 shows a cross section micrograph of such an optimized reinforced sol-gel TBC.

In addition, the effect of pre-oxidizing the bond coat on the cyclic oxidation behaviour of the sol-gel TBCs is investigated.

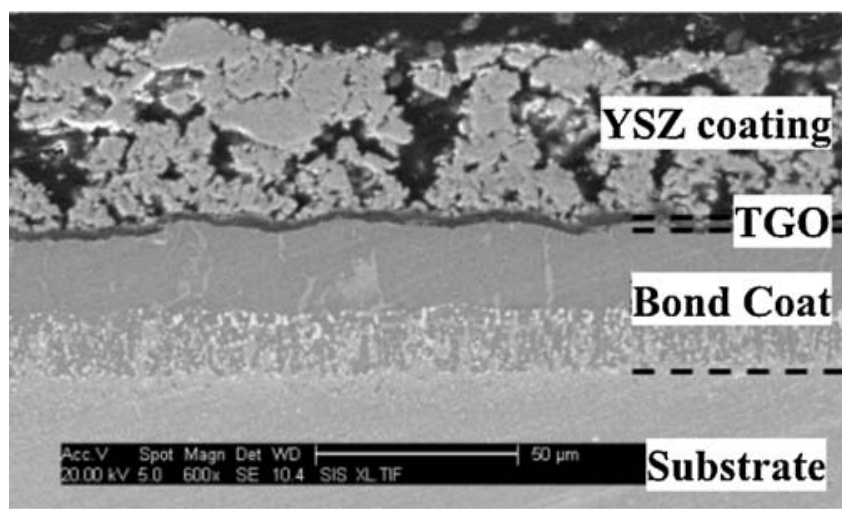

Fig. 2. Cross-section SEM micrograph of a sol-gel TBC.

As a matter of fact, during post-processing heat treatment such as cyclic oxidation, a TGO - consisting in an alumina layer acting as a diffusion barrier - forms and grows at the $\mathrm{BC} / \mathrm{TBC}$ interface. It is assumed that prior to the stable $\alpha-\mathrm{Al}_{2} \mathrm{O}_{3}$, transient metastable alumina phase (such as $\gamma-\mathrm{Al}_{2} \mathrm{O}_{3}, \delta-\mathrm{Al}_{2} \mathrm{O}_{3}$ or $\theta$ $\mathrm{Al}_{2} \mathrm{O}_{3}$ ) conferring poor properties to the system (weak adhesion, high growth rate, etc.) when they transform into stable $\alpha-\mathrm{Al}_{2} \mathrm{O}_{3}$, may form during high temperature exposure. ${ }^{10}$ Therefore these transient alumina phases are avoided in thermal barriers system to the benefit of the stable $\alpha-\mathrm{Al}_{2} \mathrm{O}_{3}$ which is a dense, slowly growing, adherent and protective TGO well known for significantly contributing to extent TBC life. ${ }^{11}$ A way to control and favour the $\alpha-\mathrm{Al}_{2} \mathrm{O}_{3}$ formation is the pre-oxidation of the BC. ${ }^{12,13}$

In this paper, the pre-oxidation of the initial AM1 superalloys substrate coated with NiPtAl bond coat is carried out at $950{ }^{\circ} \mathrm{C}$ for $2 \mathrm{~h}$ in a secondary vacuum of oxygen $\left(5 \times 10^{-4} \mathrm{mbar}\right)$. Grazing incident XRD, adapted for surfaces and thin films study is used to check the crystal structure of the resulting alumina TGO.

Data concerning the main processing steps (pre-oxidation, sintering heat treatment, reinforcement by spray coating) to produce various grades of sol-gel TBCs are summarized in Table 1. Note that specimenS5 corresponds to the most advanced grade processed using the fully optimized parameters.

\subsection{Strain evolution monitoring by in situ synchrotron $X$-ray diffraction}

As previously mentioned, processing sol-gel TBCs includes a specific heat treatment at $1100^{\circ} \mathrm{C}$ to promote the sintering 
Table 1

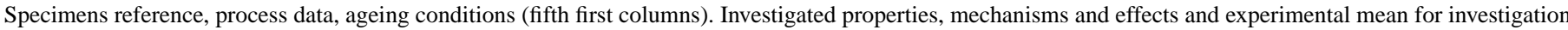
(sixth column).

\begin{tabular}{|c|c|c|c|c|c|}
\hline \multirow[t]{2}{*}{ Specimen } & \multicolumn{3}{|c|}{ Process data } & \multirow{2}{*}{$\begin{array}{l}\text { Cyclic oxidation ageing } \\
\text { Number of } 1 \text { h-oxidation } \\
\text { cycles at } 1100^{\circ} \mathrm{C}\end{array}$} & \multirow{2}{*}{$\begin{array}{l}\text { Effect investigated and mean } \\
\text { of investigation }\end{array}$} \\
\hline & $\begin{array}{l}\text { Pre- } \\
\text { oxidation }\end{array}$ & $\begin{array}{l}\text { Sintering at } 1100^{\circ} \mathrm{C} \\
\text { (heating/cooling rate-dwell } \\
\text { time and temperature) }\end{array}$ & $\begin{array}{l}\text { Reinforcement by } \\
\text { spray-coating }\end{array}$ & & \\
\hline S1 & No & $\begin{array}{l}\text { In situ in synchrotron XRD } \\
\text { furnace }\left(100^{\circ} \mathrm{C} / \mathrm{h}-1 \mathrm{~h} \text { at }\right. \\
\left.600^{\circ} \mathrm{C}\right)\end{array}$ & No & 0 & $\begin{array}{l}\text { Sintering mechanisms by } \\
\text { synchrotron XRD }\end{array}$ \\
\hline $\mathrm{S} 2$ & No & $\begin{array}{l}\text { In situ synchrotron XRD } \\
\text { furnace }\left(100^{\circ} \mathrm{C} / \mathrm{h}-1 \mathrm{~h} \text { at }\right. \\
\left.600^{\circ} \mathrm{C}\right)\end{array}$ & No & $\begin{array}{l}5 \text { cycles in situ in synchrotron } \\
\text { XRD }\end{array}$ & $\begin{array}{l}\text { Impact of first/early cyclic } \\
\text { oxidation by synchrotron } \\
\text { XRD }\end{array}$ \\
\hline S3 & No & Ex situ in furnace $50^{\circ} / \mathrm{h}$ & No & 640 & $\begin{array}{l}\text { Effect of pre-oxidation on the } \\
\text { cyclic oxidation life/cyclic } \\
\text { oxidation rig }\end{array}$ \\
\hline S4 & Yes & Ex situ in furnace $50^{\circ} / \mathrm{h}$ & No & 1025 & $\begin{array}{l}\text { Effect of pre-oxidation on the } \\
\text { cyclic oxidation life/cyclic } \\
\text { oxidation rig }\end{array}$ \\
\hline S5 & Yes & Ex situ in furnace $50^{\circ} / \mathrm{h}$ & Yes & 1480 & $\begin{array}{l}\text { Performance of optimized } \\
\text { sol-gel TBC versus EB-PVD } \\
\text { TBC/cyclic oxidation rig }\end{array}$ \\
\hline
\end{tabular}

of the ceramic top-coat and the induced formation of a crack network throughout the coating.

To investigate the mechanisms involved during sintering, the dynamic evolution of the internal elastic strain/stress as the TBC system is heated, then held at $1100{ }^{\circ} \mathrm{C}$ and finally cooled down to room temperature is monitored using synchrotron radiation. Indeed, as the formation of the crack network results from the time dependent stress release occurring as sintering progresses, the detailed mechanisms involved in the initiation and the propagation of cracks, might be appreciated by analyzing the time related evolution of strain within the TBC. In situ time-resolved techniques such as real-time synchrotron X-ray diffraction, allowing to monitor both the shape evolution and the shift of diffraction peaks versus time as temperature changes, is particularly adapted to analyze strain variation as well as phase transformation during high temperature exposure (heat treatment, isothermal oxidation, cyclic oxidation). ${ }^{14-17}$ The technique allows the real-time continuous monitoring of diffraction peak shifts under specific conditions such as mechanical loading, high temperature holding, heating and cooling at different rates, etc., The analysis of the peak position, shape and width can provide relevant information on the evolution of both the internal "uniform" strain and the microstructure. ${ }^{18}$ Indeed, a uniform "macro-strain" causes the isotropic expansion (or contraction) of the crystal unit cell, thus leading to a uniform change in the lattice parameters that results in a shift of the diffraction peaks.

In addition, nanostructural deviations from a perfect crystal, i.e. when a few atoms move locally apart from their equilibrium positions, may result in a broadening of the peak diffraction. As a consequence, small crystallite size associated to a high density of grain boundaries, defects at the atomic scale such as stacking faults, vacancies, dislocations or "micro-strain", as well as a poor crystallinity systematically result in a peak broadening.
The use of the high energy X-rays of ID15B at ESRF with very high measurement speeds, allows to successfully and accurately monitor in situ both the continuous shift and the broadening of Bragg peaks. Shift is related to the lattice spacing evolution, i.e. to the elastic macro-strain at the scale of the phase and broadening is related to lattice defect, grain size, i.e. the micro-strain and the sintering.

A resistive heater showing a "sandwich geometry" instrumented with two openings allowing X-ray to pass through, was mounted at ID15B and diffraction patterns were recorded simultaneously in transmission mode on the two-dimensional (2D) PIXIUM detector placed at $746.35 \mathrm{~mm}$ from the specimen. The incident energy is $87.1 \mathrm{keV}$.

Specimen S1 consisting of a sol-gel TBC deposited on NiPtAl bond coated AM1 super alloy substrate using dip coating, was first heat treated in air as followed: (i) heat from room temperature up to $600^{\circ} \mathrm{C}$ at a heating rate of $100^{\circ} \mathrm{C} / \mathrm{h}$, (ii) hold $1 \mathrm{~h}$ at $600^{\circ} \mathrm{C}$ then heat up to $1100^{\circ} \mathrm{C}$ at a rate of $100^{\circ} \mathrm{C} / \mathrm{h}$, (iii) hold $2 \mathrm{~h}$ at $1100^{\circ} \mathrm{C}$ then continuous cool to room temperature at a rate of $100^{\circ} \mathrm{C} / \mathrm{h}$. Temperature was measured by a S-type thermocouple, previously calibrated, and located at the sample surface. Note that both heating and cooling rates are different from the "optimal" heat treatment parameters $\left(50^{\circ} \mathrm{C} / \mathrm{h}\right)$ in order to limit the time of experiment.

Due to very intense diffraction peaks from the single crystal substrate, an appropriate beam size of $300 \mu \mathrm{m}$ by $100 \mu \mathrm{m}$ was chosen to probe only the sol-gel TBC. A schematic drawing of the experimental set-up with this "grazing incident" geometry is shown in Fig. 3.

The raw data consist in 2D diffraction patterns (Fig. 4a) obtained every $30 \mathrm{~min}$ with an acquisition time of 40 seconds, which is long enough to obtain well defined diagrams. The continuous Debye-Scherrer rings induced by the YSZ coating 

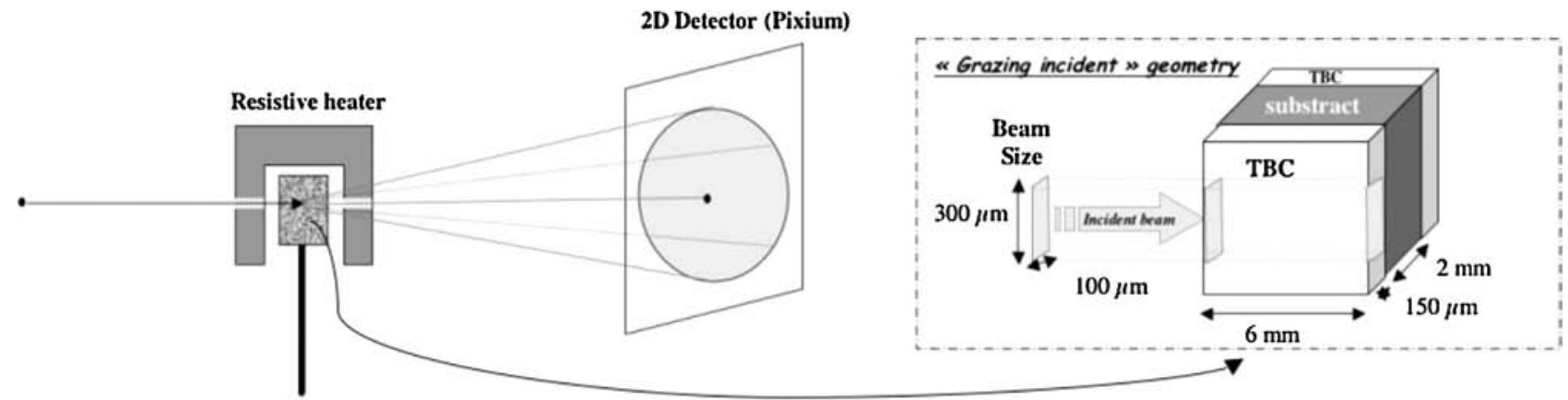

a)

b)

Fig. 3. Sketch of the high-energy X-ray transmission set-up (a) and details of the sample geometry and X-ray beam size (b).

(a)
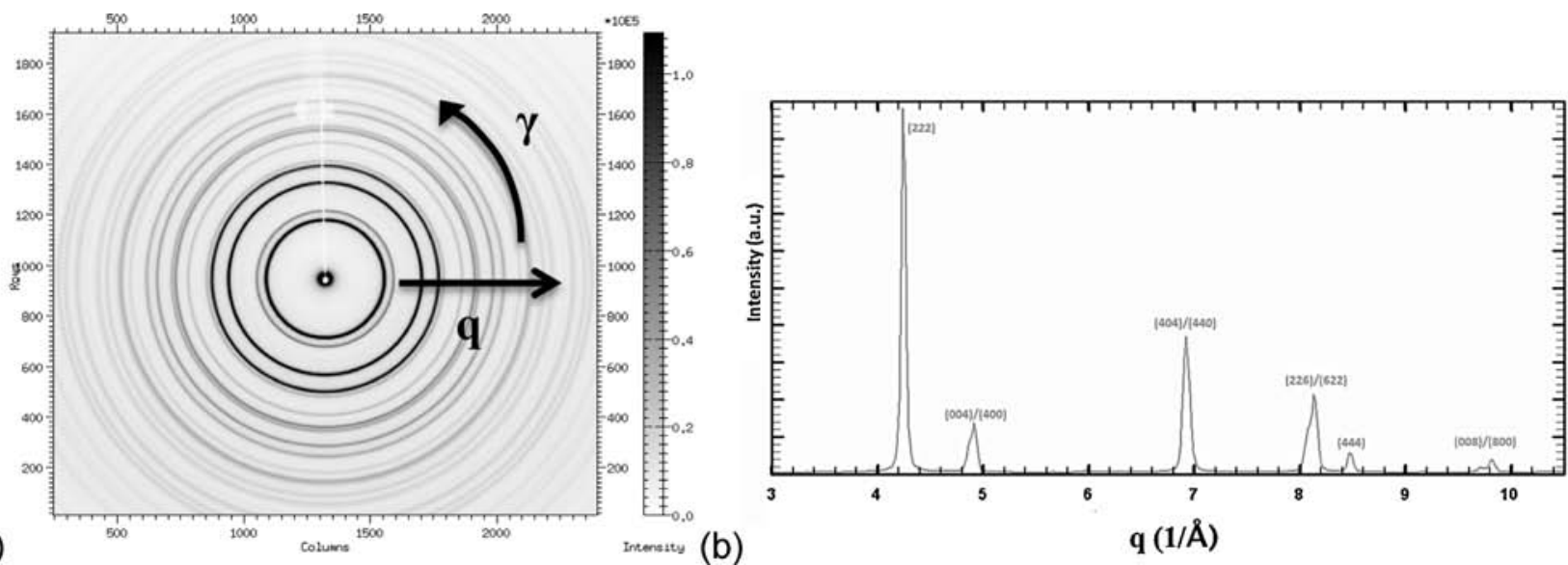

Fig. 4. Typical 2D (a) and 1D (b) diffraction pattern (note that $\gamma$ is the azimuthal angle and $\mathrm{q}$ is the radial direction).

confirm that sol-gel processing results in a randomly oriented TBC microstructure. Integration along the azimuthal angle $\gamma$ allows to plot the conventional 1D diffraction pattern I(q) displayed in Fig. $4 \mathrm{~b}$, with the radial direction $\mathrm{q}$ being related to the diffraction angles $2 \theta$ by: $q=4 \pi / \lambda \sin \theta$. To avoid any damage of the 2D detector, a "beam stop" made of lead was installed to protect from the diffuse intensity of the direct beam.

Using the same experimental set-up and by moving up and down the resistive heater, five 1 -h oxidation cycles at $1100^{\circ} \mathrm{C}$ were imposed to a sol-gel TBC specimen (S2 in Table 1), similarly processed and heat-treated than specimen $\mathrm{S} 1$. The elementary oxidation cycle includes $5 \mathrm{~min}$ heating up to $1100^{\circ} \mathrm{C}$, $55 \mathrm{~min}$ holding and $20 \mathrm{~min}$ cooling down to room temperature. XRD data were collected with frequencies and acquisition times that depend on the considered time period of the cycle. Indeed, during heating/cooling and holding stages, 2D diffraction patterns were respectively monitored every $10 \mathrm{~s}$ (acquisition time $4 \mathrm{~s}$ ) and every $10 \mathrm{~min}$ (acquisition times $40 \mathrm{~s}$ ).

\subsection{Cyclic oxidation tests}

Cyclic oxidation tests are performed in a specific dedicated automated rig instrumented with a CCD camera to monitor in a real time basis the evolution of the specimen surface upon the air-forced 5 min cooling following the various cumulated $5 \mathrm{~min}$ heating plus 1-h holding at $1100^{\circ} \mathrm{C}$. Individual CCD images are extracted from the video recording to be treated using image analysis software. From those experimental data evaluated in situ, the evolution of the surface as a function of time following each cycle, and so the overall surface damage kinetics, can be derived.

First, two unreinforced specimens respectively pre-oxidized (S4) and non-pre-oxidized (S3) were cyclically oxidized to evaluate the impact of the initially grown $\mathrm{Al}_{2} \mathrm{O}_{3}$ diffusion barrier on the lifetime.

In addition, a fully optimized sol-gel TBC (S5) processed using the appropriate sintering heat treatment, a reinforcement by crack filling and a pre-oxidation as well as an EBPVD TBC are concurrently oxidized to evaluate and compare their overall performances.

\section{Results and discussion}

\subsection{Strain evolution during sintering}

A precise investigation of the elastic strain evolution within the TBC upon sintering was carried out by studying the shift of the diffraction peak as illustrated in Fig. 5 for the 


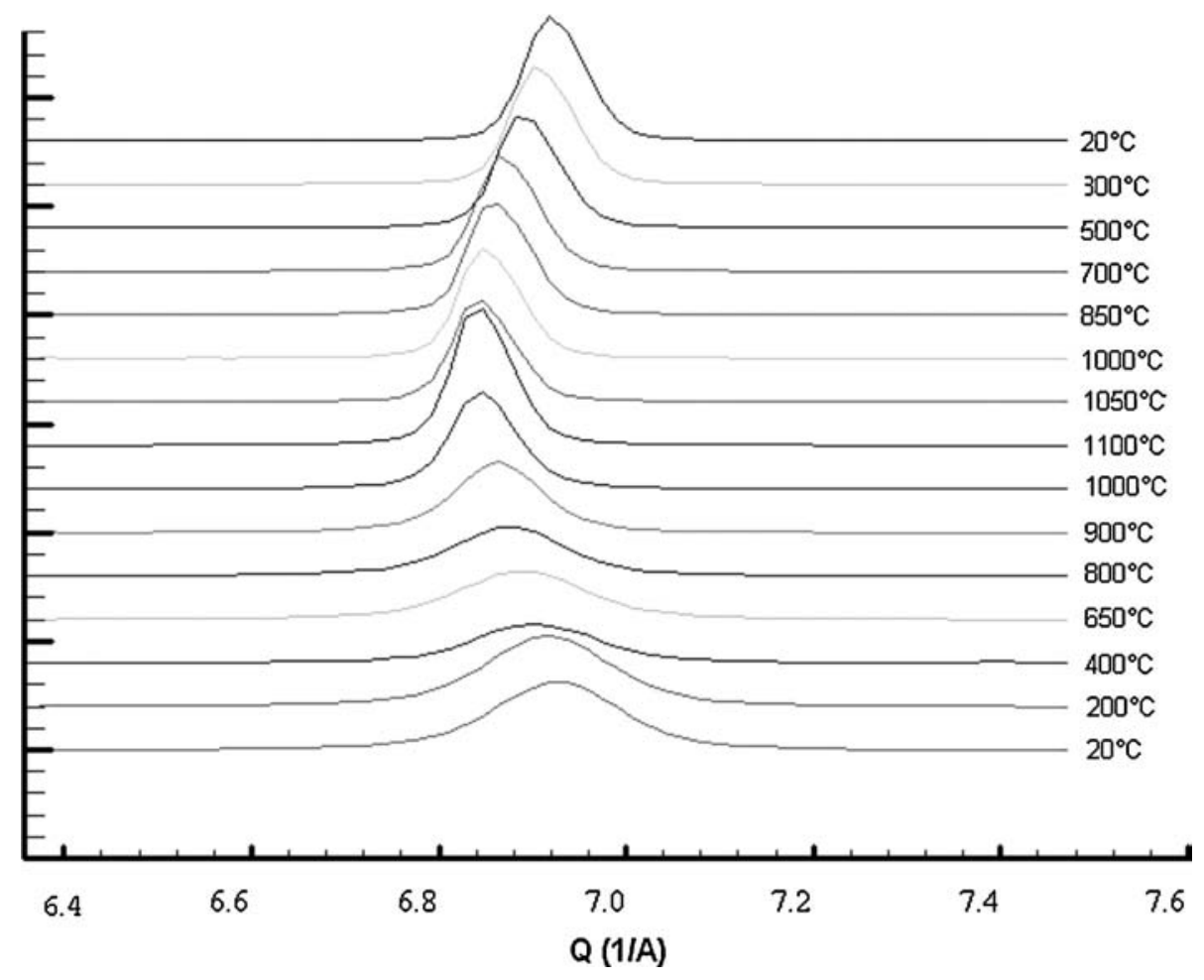

Fig. 5. Series of 1D diffraction patterns $(I=f(Q))$ for the $(440)$ peaks of the $\mathrm{YSZ}$ on heating from $20^{\circ} \mathrm{C}$ to $1100{ }^{\circ} \mathrm{C}$ (seven bottom plots) and cooling from $1100{ }^{\circ} \mathrm{C}$ to $20^{\circ} \mathrm{C}$ (seven top plots).
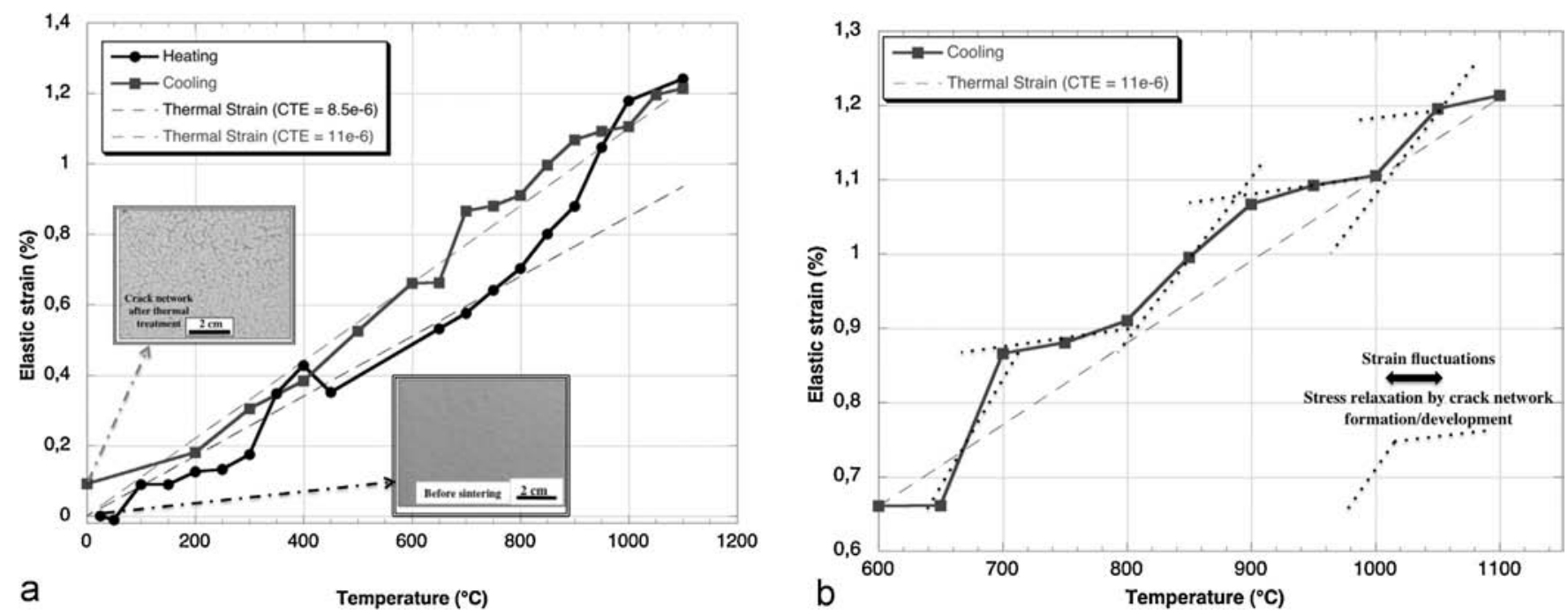

Fig. 6. (a) Elastic strain evolution of (440) planes on heating and cooling (lattice strain is compared with the expected evolution resulting from thermal expansion only). (b) Enlargement of strain fluctuations from $1100^{\circ} \mathrm{C}$ to $600^{\circ} \mathrm{C}$ during cooling.

tetragonal (4 4 0) reflection of the yttria stabilized zirconia (YSZ) constituting the TBC.

The corresponding Bragg peak positions were obtained by fitting the (440) reflection using Split Pseudo-Voigt functions that were particularly well suited for most of the YSZ peaks. Note that, using this fitting procedure, the relative error on the peak position $(\Delta d / d)$ is very low, typically $1 \times 10^{-3}(0.1 \%)$. Fig. 6 shows the strain $\left(\varepsilon_{T}^{440}\right)$ evolution versus the temperature $T$ corresponding to the $(440)_{\text {YSZ }}$ reflection. For any $(h k l)$ reflection, the strain $\varepsilon_{T}^{h k l}$ is expressed as:

$\varepsilon_{T}^{h k l}=\frac{d_{T}^{h k l}-d_{R T}^{h k l}}{d_{R T}^{h k l}}$

where $d_{T}^{h k l}$ is the interplanar spacing for $(h k l)$ planes at a given temperature $T$ and $d_{R T}^{h k l}$ is the reference, stress-free interplanar 


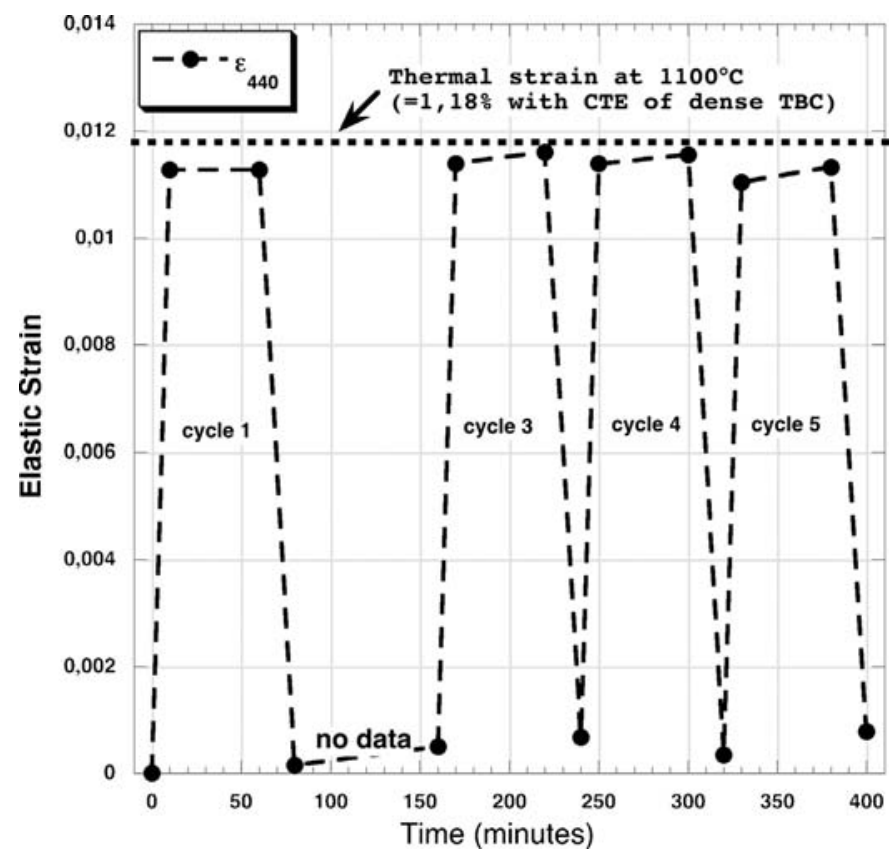

Fig. 7. Elastic strain evolution of (440) planes during early cycle of oxidation (heating for $10 \mathrm{~min}$, holding at $1100^{\circ} \mathrm{C}$ for $50 \mathrm{~min}$ and cooling for $20 \mathrm{~min}$ ).

spacing at room temperature. Dotted lines correspond to the theoretical elastic thermal strain $\left(\varepsilon_{\text {Thermal }}=\alpha_{l} \Delta T\right)$ occurring during temperature changes $(\Delta T)$ either upon heating (grey) or cooling (black) of the stress-free YSZ. It is assumed that the linear coefficient of thermal expansion (CTE or $\alpha_{l}$ ) of the YSZ varies with the porosity in the material, ${ }^{19}$ that obviously changes during heating and most significantly during holding at $1100^{\circ} \mathrm{C}$ where sintering fully completes. As a consequence, the CTE of a porous non-sintered YSZ, i.e. $8.5 \times 10^{-6}{ }^{\circ} \mathrm{C}^{-1}$ and that of a dense sintered YSZ, i.e. $11 \times 10^{-6}{ }^{\circ} \mathrm{C}^{-1}$ are respectively used during heating and cooling time periods.

Upon heating, the elastic strain $\varepsilon_{T}^{440}$ is clearly not linear, revealing that other contributions than the thermal expansion have to be considered.

First, from room temperature to roughly $450{ }^{\circ} \mathrm{C}$, strain fluctuations may be related to the calcination of residual organics compounds that likely decompose in the range $100-400{ }^{\circ} \mathrm{C} .^{20}$ This desorption might slightly increase the contact between YSZ particle surfaces and thus contribute locally to a lower shrinkage resulting in an additional capillary strain around $350{ }^{\circ} \mathrm{C} .{ }^{21}$ Further evolution above $450^{\circ} \mathrm{C}$ only results from thermal expansion as experimental data perfectly fit the plot of the thermal strain versus the temperature.

From $700^{\circ} \mathrm{C}$, a drastic increase of the elastic strain and correlatively the elastic stress is observed as the experimental plot strongly deviates from the calculated linear thermal strain evolution. This probably corresponds to both the onset of the YSZ sintering and the concomitant growth of the $\mathrm{Al}_{2} \mathrm{O}_{3}$ TGO (thermally grown oxide) layer. The elastic strain $\left(\varepsilon^{e l}\right)$ is then the sum of the thermal expansion mismatch strain due to the CTE difference between the bond coat (BC) and the YSZ $\left(\varepsilon_{T h}^{e l}=\right.$ $\left.\left(\alpha_{Y S Z}-\alpha_{B C}\right) \Delta T\right)$ and the strain due to the constrained sintering $\left(\varepsilon_{S}^{e l}\right)$. Indeed, while sintered, the metallic substrate - though expanding upon heating - restrains the shrinkage of the YSZ ceramic leading to the occurrence of enhanced tensile strain and stress. Note that assuming an isotropic shrinkage, the dimensional changes during sintering of an unconstrained YSZ could be straightforwardly derived as $\Delta L / L_{0}$ (in-plane shrinkage). In addition, growth strains $\left(\varepsilon_{G}^{e l}\right)$ due to the formation and thickening of the TGO layer can be combined with thermal $\left(\varepsilon_{T h}^{e l}\right)$ and sintering strain $\left(\varepsilon_{S}^{e l}\right)$. As a matter of fact, high tensile stress in the TGO is reported. ${ }^{22,23}$ It is mainly attributed to the volume reduction resulting from the transformation of the transition alumina into the most stable $\alpha-\mathrm{Al}_{2} \mathrm{O}_{3}$ during the earlier growth stages. This growth stress might also contribute to an increase of the tensile strain into the YSZ at least until the phase transformation into the stable $\alpha-\mathrm{Al}_{2} \mathrm{O}_{3}$ is completed. Indeed, as reported, ${ }^{23,24}$ further growth of stable $\alpha-\mathrm{Al}_{2} \mathrm{O}_{3}$ only develops low stress.

Between $700{ }^{\circ} \mathrm{C}$ and $1000{ }^{\circ} \mathrm{C}$, thermal stress as well as sintering stress and TGO growth stress jointly contribute to the significant increase of the elastic stress and strain experimentally measured within the TBC.

From $1000^{\circ} \mathrm{C}$, the elastic strain progressively stabilizes, the slope of the strain-temperature plot being much lower. At this temperature and above, the network of micro-cracks - prone to release the in-plane tensile stress and associated strain - initiates and continuously develops through a two-dimensional crack propagation within the thickness of the YSZ. Upon cooling, particularly in the high temperature range between $1100^{\circ} \mathrm{C}$ and $700{ }^{\circ} \mathrm{C}$, the elastic strain shows as well instabilities, as indicated by the successive steps in Fig. 6b. They likely correspond to the further development of the cracks network leading to a substantial release of stress stored in the YSZ during heating and holding at $1100^{\circ} \mathrm{C}$.

Due to the mismatch between thermal expansion coefficients of the YSZ ceramic coating and the metallic substrate, the metal tends to contract on cooling more than the ceramic. This provokes the development of additional stress into the YSZ layer whose stiffness increased during sintering and thus response to mechanical loading changes. One way to release this additional stress is to form new or develop existing micro-cracks as detailed in the insert in Fig. 6. At $600{ }^{\circ} \mathrm{C}$ and below, the stress in the fully dense YSZ is assumed to be extensively released and the remaining strain only results from the thermal contraction as perfectly highlighted by the fairly good agreement between the experimental and calculated data plotted in Fig. 6. Note that returning to room temperature leaves some residual tensile strain - and so residual tensile stress - in the TBCs revealing that the complete released is not achieved. Residual stress within TBCs after temperature exposure and cooling are known to be mainly compressive, particularly at the interface TBC/TGO-bond coat as a consequence of the significant mismatch in the coefficients of thermal expansion between the two materials. This likely results in a continuous and progressive change in stress magnitude throughout the entire thickness of the TBC, gradually ranging from compression at the interface with the substrate to tension at the outer surface in contact with the oxidizing atmosphere. As the X-ray beam size used in XRD experiments is identical to the TBC thickness, input reflection collected to 


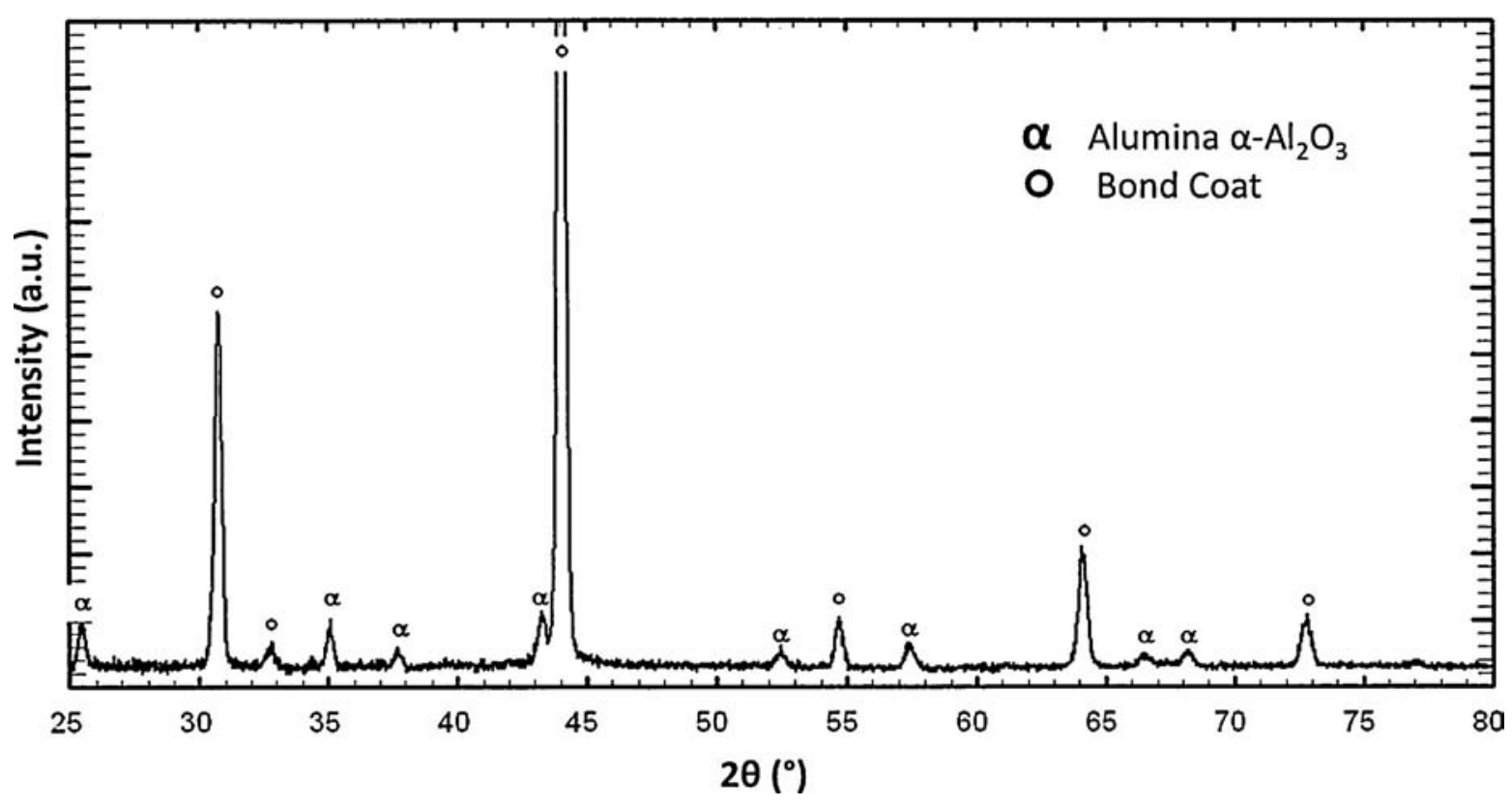

Fig. 8. Grazing incidence X-ray diffractogram for the pre-oxidized sample.

(a)

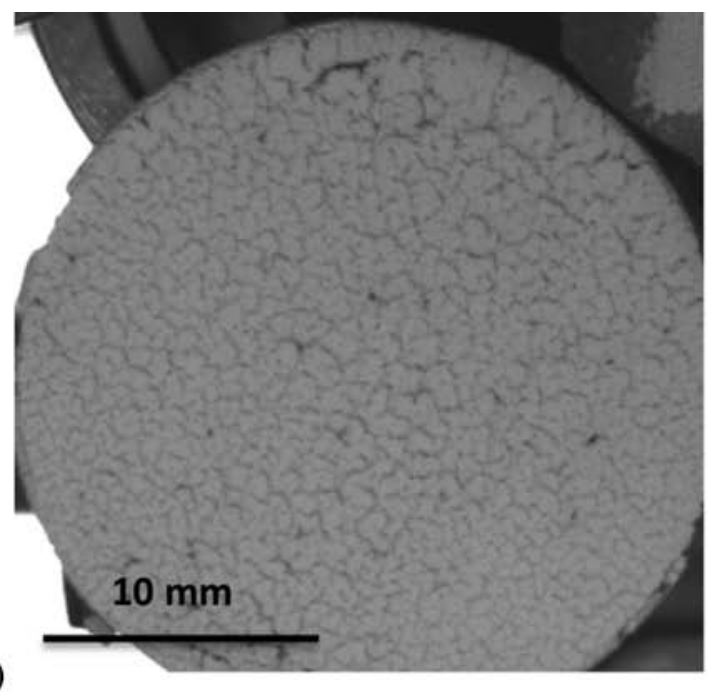

(b)

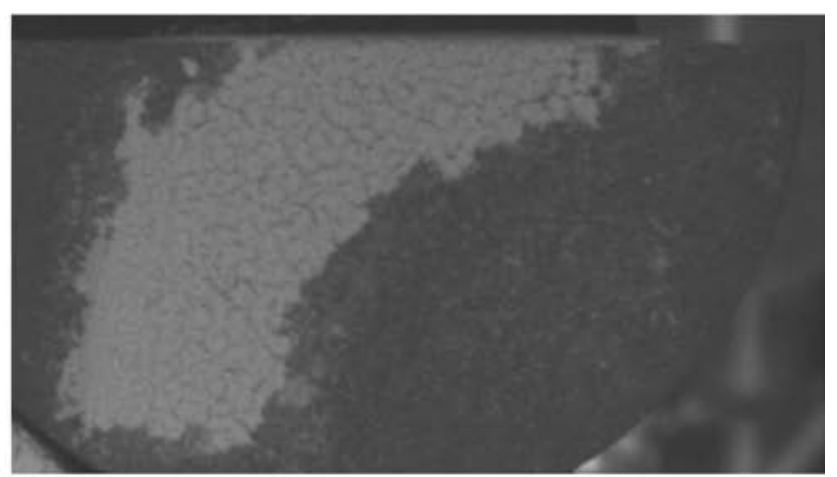

Fig. 9. Sol-gel TBC surface of (a) a pre-oxidized sample after 1025 one-hour cycles and (b) a non-preoxidized sample after 640 one-hour cycles.

calculate strain, convolutes data extracted from the whole TBC from its inner interface to its outer surface. As a consequence, the calculated strain in the coating must be regarded as a mean quote, averaging interfacial, close-to-surface and bulk values (plane strain).

The evolution of the peak shape, clearly revealed in Fig. 6a, can be beneficially analyzed to inform on the structural modification that occurs during sintering. Namely, the sharpening and the increase in intensity of the Bragg peaks, especially upon heating from $900^{\circ} \mathrm{C}$, can be related to the three successive stages commonly reported to account for the whole sintering process to complete. ${ }^{25}$ Within the first stage, particles rearrange which contributes to enhance contact efficiency and consequently shrinkage and density. The second stage promotes the densification and the reduction of the pores size. The third stage corresponds to the elimination of isolated pores prone to further enhance densification of the material and favour grain growth. The highly pronounced sharpening of the Bragg peaks, particularly from $900^{\circ} \mathrm{C}$, can be thus related mainly to this ultimate stage of sintering, from $900^{\circ} \mathrm{C}$ to $1100^{\circ} \mathrm{C}$, where noticeable grain growth generally occurs.

Investigating the elastic strain evolution in the $\mathrm{TBC}$ in a real time basis clearly reveals the importance of controlling the heat treatment where sintering of the TBC associated to the formation of the crack network occurs. Indeed, the establishment of a perfectly stabilized crack network resulting from a complete sintering of the TBC should be achieved before using TBCs in real industrial conditions. This is indeed of primary importance 
to avoid any supplementary strain and stress increase associated to a possible in-service completion of the sol-gel TBC sintering process.

Furthermore, as previously mentioned, growth stress within the TGO may also contribute to a large extent to the increase of the residual stress into the sol-gel TBC, particularly during further oxidation cycles generally performed with high heating and cooling rates. The possibility to limit growth stress using an initial thoroughly controlled pre-oxidation of the substrate before sol-gel deposition and the impact on the durability upon cyclic oxidation is discussed in the next section.

\subsection{Cyclic oxidation behaviour of sol-gel TBC}

\subsubsection{Evolution of the elastic strain during early stages of thermal cycling oxidation}

As to investigate any possible change in strain provoked by cyclic oxidation, the tetragonal (440) YSZ reflection of a non-reinforced sol gel TBC (specimen S2) upon the first five $1 \mathrm{~h}$-cycles at $1100{ }^{\circ} \mathrm{C}$ was monitored in situ. The impact of these early oxidation cycles is appreciated both by analysing data obtained right before and after each individual cycle and comparing of elastic strain at the beginning and end of the exposure at dwell temperature $\left(1100^{\circ} \mathrm{C}\right)$. Shown in Fig. 7 are the evolutions of the elastic strain upon first, third, fourth and fifth cycles, calculated using the reference room temperature inter-planar distance right before the first cycle, as well as the theoretical thermal strain estimated for a fully dense stress-free YSZ $\left(\varepsilon_{\text {Thermal }}=\alpha_{l} \Delta T\right)$ at $1100{ }^{\circ} \mathrm{C}$.

The first thermal cycle does not generate noticeable overall variation of the elastic strain. However, during exposure at $1100{ }^{\circ} \mathrm{C}$, the elastic strain in the TBC, essentially constant, is slightly smaller than the expected elastic thermal expansion. This can result from the intrinsic nature of the cycle including fast heating and quite short exposure, which likely establishes a significant temperature gradient throughout the thickness of the TBC. As a result the strain can be highly different depending on the location within the TBC. The elastic strain calculated from $\mathrm{X}$-ray data convoluted from the whole thickness of the TBC can consequently differ from the sole thermal strain $\varepsilon_{\text {Thermal }}$, which would be homogeneously distributed only if steady state was ensured.

Upon further cyclic exposure (3rd, 4th and 5th cycles) and conversely to the first cycle, an increase of the strain, very similar for each cycle, is measured while the TBC is held at $1100{ }^{\circ} \mathrm{C}$. This strongly suggests that the TBC mechanical response to temperature exposure is impacted by various additional effects such as the mismatch in thermal expansion coefficient between the YSZ, the TGO and the bond coat, specific deformation mechanisms - especially creep - occurring at high temperature in the $\mathrm{BC}$, TGO and TBC as well as constraint typically due to the continuous slow growth of the TGO. Indeed, literature reports that $\mathrm{NiPtAl} \mathrm{BC}$ is expected to yield at temperature above $600^{\circ} \mathrm{C}^{26}$ and deforms by creep at $1100^{\circ} \mathrm{C}$, as $\mathrm{TGO}^{3,27}$ and $\mathrm{TBC}$ can do as well. As a consequence, creep of the bond coat is assumed to impose additional deformation to the sol-gel TBC resulting in the slight elastic strain increase occurring during exposure at $1100{ }^{\circ} \mathrm{C}$ (Fig. 7).

Beyond the progressive, time dependent evolution of strain during isothermal exposure, it is interesting to note that the strain before and after each elementary cycle tends to change, either increasing (3rd and 5th cycles) or decreasing (4th cycle). This unambiguously indicates that in all cases residual strain and stress establish within TBC. However, after cooling, residual stress is heterogeneously distributed throughout the TBC thickness, from essentially compressive at the top of the TBC to tensile at the $\mathrm{BC} / \mathrm{TGO}$ interface. Result from X-ray analysis, standing for an overall mean value, partially conceals the strain heterogeneity.

Nevertheless it can be concluded that as soon as the very first oxidation cycles are imposed to the TBC, various deformation mechanisms can operate to modify and accumulate residual strain, including typically:

(i) creep assumed to occur mainly in the $\mathrm{BC}$ during isothermal exposure at $1100^{\circ} \mathrm{C}$ that likely elongates the $\mathrm{TBC}$,

(ii) thickening of the TGO, which develops growth stress during heating as well as large residual compression stress on cooling to room temperature as its CTE is lower than that of both the $\mathrm{BC}$ and the $\mathrm{TBC}$,

(iii) mismatch in CTE operating both during heating and cooling.

It is interesting to point out that these observations may be also related to the possible occurrence of interfacial rumpling. Indeed, whereas this undulation development is not fully understood, several works attribute rumpling to combined effects such as coating-substrate thermal expansion coefficient mismatch and cyclic plastic strains and creep in the bond coat. Rumpling is a common, frequently observed material response to cyclic oxidation, which develops preferentially under such conditions and is only little pronounced following isothermal oxidation. It corresponds to the ability of the bond coat, depending on its intrinsic mechanical properties, to accommodate more or less the plastic deformation related to stress produced by thermal cycling and TGO growth. Development of rumpling in the bond coat close to the interface with alumina affects the deformation of the TGO and the top-coat TBC. As a matter of fact, synchrotron X-ray diffraction, well suitable for estimating residual strain and stress, can beneficially be used to address this important mechanism typical of cyclic oxidation of TBC and particularly detrimental regarding durability of the system.

Finally, in order to assess the effects of the cyclic oxidation on the evolution of the residual strain and stress on the TBC life duration and failure mechanisms, thermal expansion coefficient mismatch as well as the onset of creep deformation into the different stacked layers (BC, TGO and TBC) should be considered from the very first cycles. 

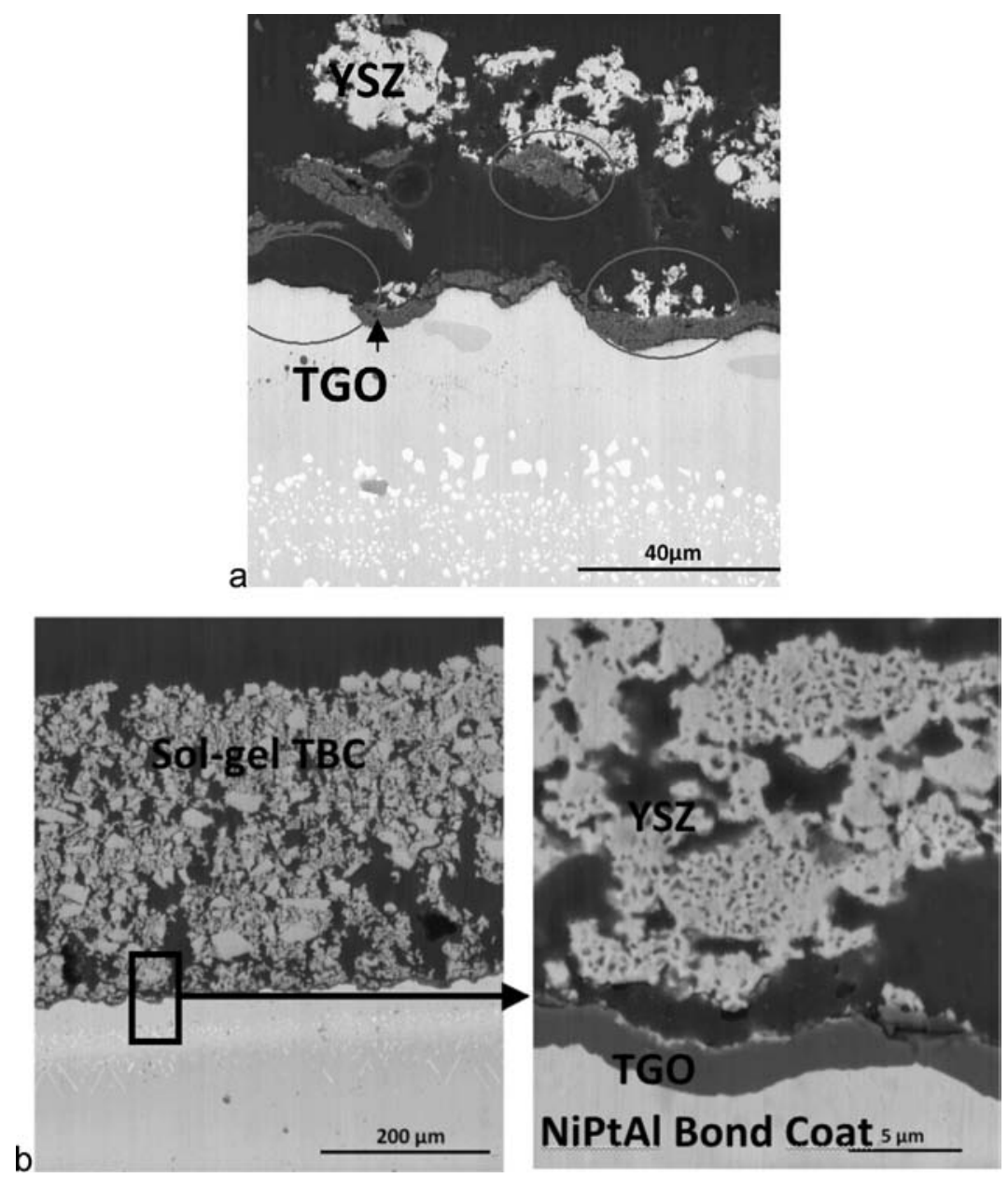

Fig. 10. SEM micrographs of the cross section of TBC systems (a) without pre-oxidation (after 640 1-h cycles) and (b) with pre-oxidation (after 1025 1-h cycles).

\subsubsection{Effect of pre-oxidation on cyclic oxidation behaviour of sol-gel TBC}

As mentioned previously, the irreversible growth of the alumina $\mathrm{Al}_{2} \mathrm{O}_{3}$ layer during the post-processing heat treatment generates prejudicial growth stress in the TBC, mainly due to the transformation of transient metastable alumina phases into stable $\alpha-\mathrm{Al}_{2} \mathrm{O}_{3}$. Preventing or at least limiting the formation of those transient phases should have beneficial effect on the resistance to cyclic oxidation. Favouring the nucleation and preferential growth of stable $\alpha-\mathrm{Al}_{2} \mathrm{O}_{3}$ can be achieved by preoxidizing the substrate prior to deposition. Pre-oxidation must be thoroughly controlled to develop pure coherent and thin alumina layer. Fig. 8 shows the grazing incidence $\mathrm{X}$-ray diffraction pattern obtained for a NiPtAl bond coat pre-oxidized $2 \mathrm{~h}$ at $900^{\circ} \mathrm{C}$ under secondary vacuum of oxygen $\left(5 \times 10^{-4} \mathrm{mbar}\right)$. To limit the depth of penetration of X-rays into the bond coat and investigate mainly the thin alumina layer, a grazing incidence angle was fixed to $\alpha=1.5^{\circ}$. Only Bragg peaks characteristic of either the bond coat or the $\alpha$-alumina are identified showing clearly that metastable phases did not form during preoxidation.

The effect of this beforehand treatment and the associated presence of a thin initial pure $\alpha$-alumina layer prior to sol-gel processing of the TBC on the cyclic oxidation behaviour is analyzed by comparing behaviour of non reinforced sol-gel TBC either pre-oxidised (specimen S4) or non pre-oxidised (specimen S3). The aspect of the outer surface of such specimens following 1025 (for S4) and 640 (for S3) $1 \mathrm{~h}$-cycles at $1100^{\circ} \mathrm{C}$ are shown in Fig. 9a and b respectively. Both specimens show identical characteristics in terms of surface morphology showing the presence of the crack network issued from the sintering heat treatment and prone to release constrained shrinkage strain as quantitatively estimated in Section 2.2. While the whole TBC shows perfect adhesion to the pre-oxidised substrate bond coat, it extensively spalled off from the substrate with no pre-oxidation. Indeed, in this former case, the surface fraction of spalled TBC, highly discohesive, largely exceeds $50 \%$ even though the number of oxidation cycles is $40 \%$ lower than for the pre-oxidised system.

Complementary SEM analysis of cross sections from the two specimens (Fig. 10) highlights two main features:

(i) Without pre-oxidation, failure, either adhesive or cohesive, occurs over different zones of the TBC system such as the interfaces bond coat/TGO and TGO/TBC as well as within the TBC itself. Note that the TGO, with thickness around $10 \mu \mathrm{m}$, shows high rumpling. 
a

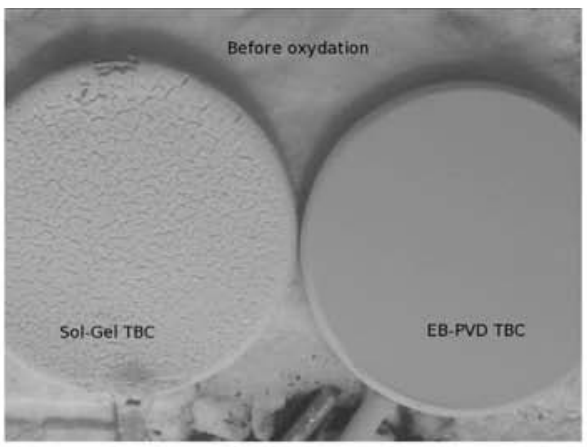

c

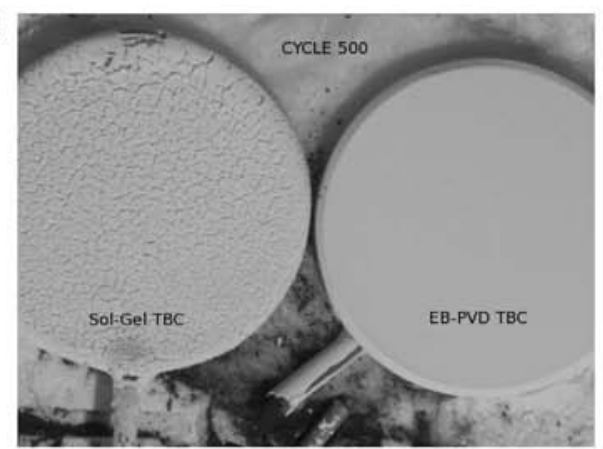

e

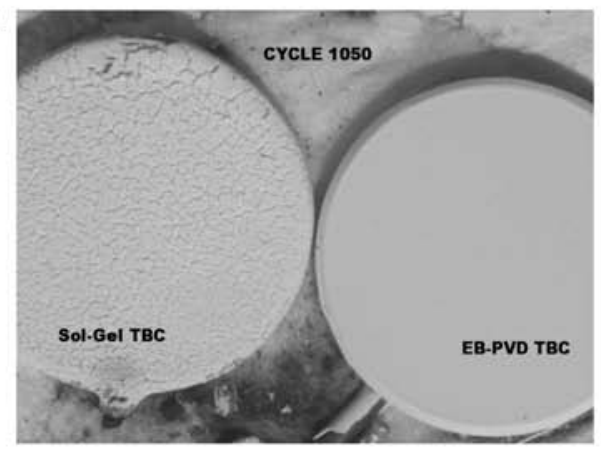

g

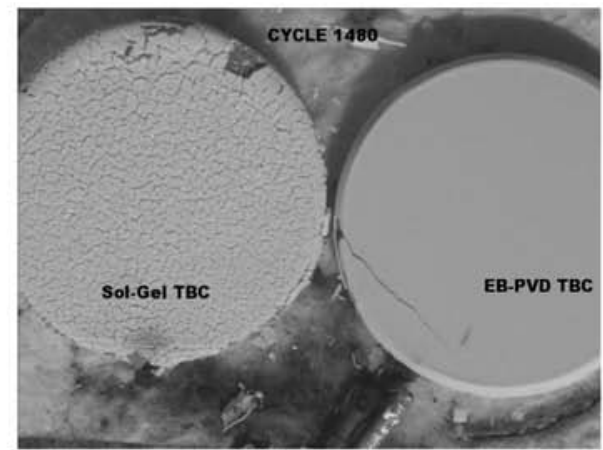

b

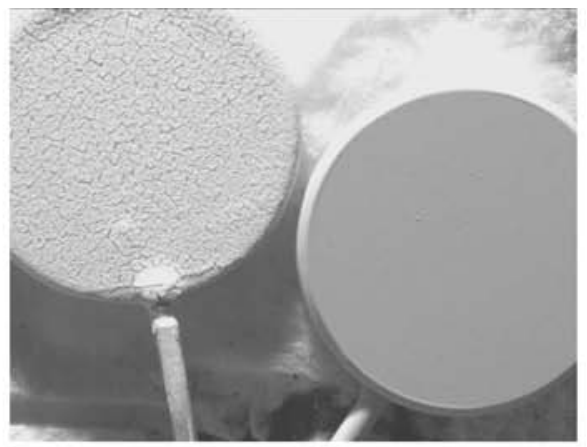

d

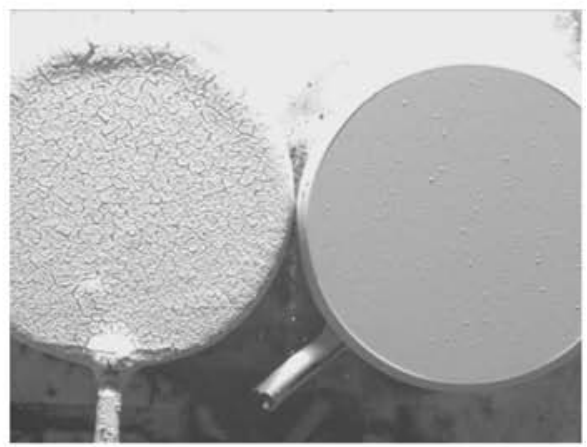

f

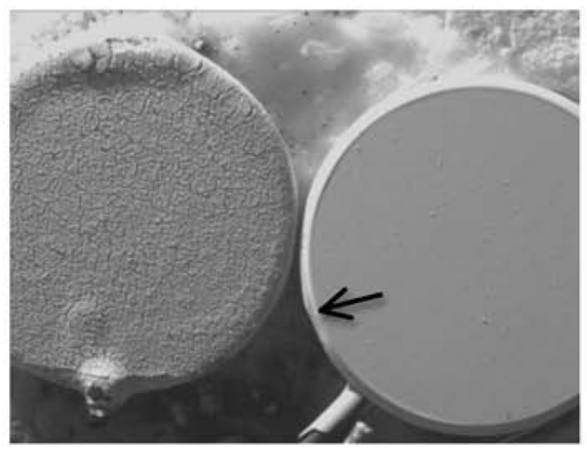

h

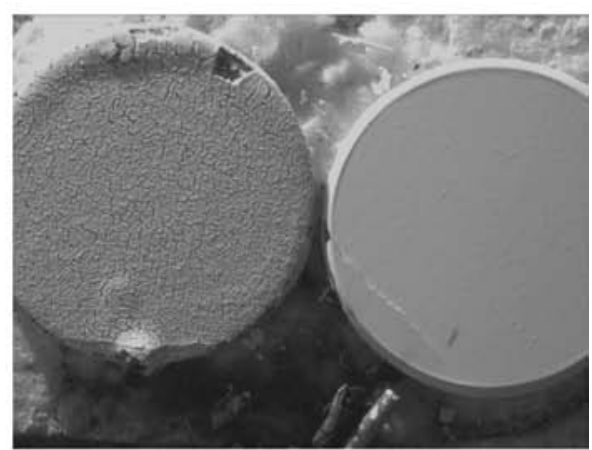

Fig. 11. Optical micrographs of the sol-gel TBC (left hand side images) and EB-PVD TBC (right hand side images) samples before cyclic oxidation (a and b), after the 500th $1 \mathrm{~h}$-cycle at $1100^{\circ} \mathrm{C}$ (c and d), after the 1050th $1 \mathrm{~h}$-cycle (e and f) and after the 1480th $1 \mathrm{~h}$-cycle ( $\mathrm{g}$ and $\mathrm{h}$ ). (Note that images b, $\mathrm{d}, \mathrm{f}$ and $\mathrm{h}$ are obtained using grazing light conditions, which enhances surface defects.)

(ii) With pre-oxidation, the TGO, much thinner (about $2 \mu \mathrm{m}$ thick) presents smoother rumpling and shows high adhesion to the bond coat.

This comparison revealed that the pre-oxidation on the initial AM1 superalloy substrate coated with $\mathrm{NiPtAl}$ at $950^{\circ} \mathrm{C}$ during $2 \mathrm{~h}$, clearly improves the cyclic oxidation behaviour of the sol-gel TBC by controlling the formation of a stable and thinner $\alpha-\mathrm{Al}_{2} \mathrm{O}_{3}$ layer adherent to the bond coat. Indeed, initial high temperature oxidation prior to $\mathrm{TBC}$ deposition results in a reduction of the oxidation rate of the TBC-coated material and concomitantly in an extended time to reach the TGO critical thickness, standing for the onset to spallation. Prejudicial issues related to the formation of metastable phase ${ }^{12}$ are thus limited 

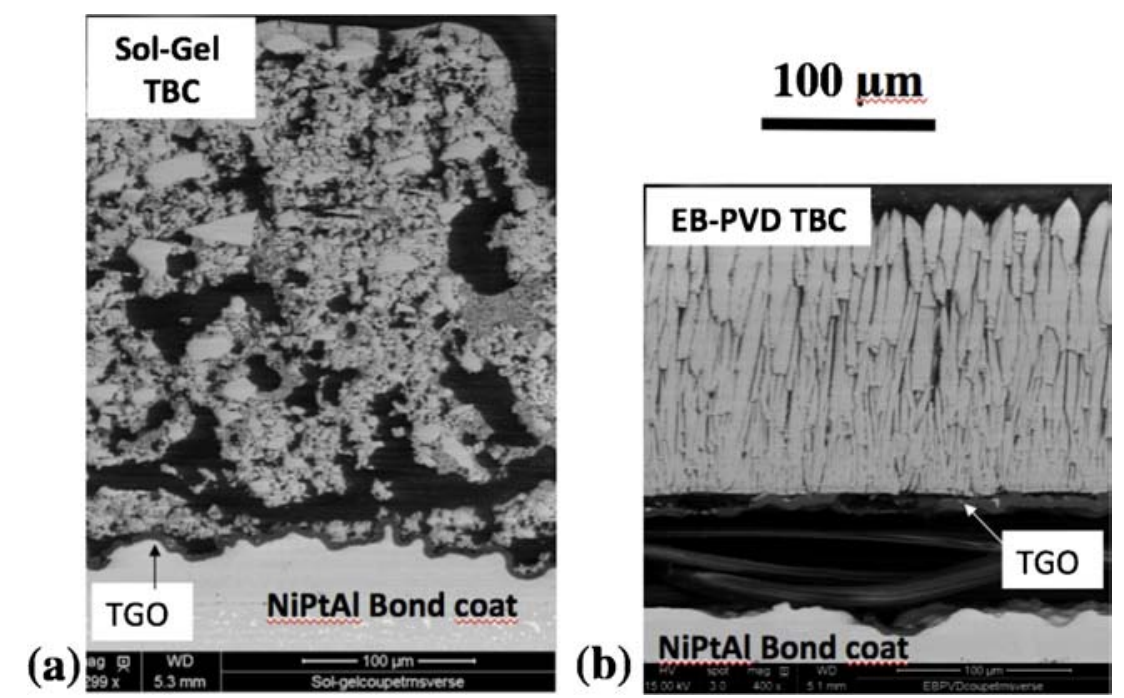

Fig. 12. SEM micrographs of the cross section of (a) the reinforced/optimized sol-gel TBC and (b) EB-PVD TBC following the 1480 th $1 \mathrm{~h}$-cycle at $1100{ }^{\circ} \mathrm{C}$.

through a significant decrease of the level of TGO growth stress as well as an enhancement of diffusion barrier properties before in-service conditions are applied. ${ }^{28,29}$

Note that the occurrence of rumpling does not depend on the specific growth mechanism of the TGO as both pre-oxidised and non pre-oxidised systems exhibit fairly corrugated interfaces. This suggests that TGO growth stress and oxidation rate do not impact rumpling significantly as also observed by Topygo and Clarke. ${ }^{30}$

Finally, this comparison confirms, the possibility of improving the cyclic oxidation behaviour by using pre-oxidation of the initial substrate and proves its feasibility and applicability to sol-gel TBC systems.

\subsubsection{Cyclic oxidation behaviour of the optimized reinforced sol-gel TBC: comparison with an EB-PVD TBC}

As previously illustrated in the literature, the failure mechanism of TBCs is well different for EB-PVD and sol-gel systems. Basically, EB-PVD TBCs generally exhibit long term resistance to spallation following cyclic oxidation exposure with very little degradation up to, say, one to two thousands numbers of one hour-cycles at $1100^{\circ} \mathrm{C}$. Once, the mechanical strain energy stored in the system and the development of rumpling are large enough for the onset to spallation, the EB-PVD TBC generally fails upon one single cooling subsequent to an ultimate exposure at high temperature. Failure affects the whole TBC or at least a large surface fraction of the TBC following the initiation and propagation of cracks at the substrate/TGO interface. In the case of sol-gel TBC, the initial crack network resulting from the sintering heat treatment, concentrates stress during cyclic exposure and acts as zones of crack formation that generally tend to propagate at the TGO/TBC interface. Individual cells, delineated by this network, can subsequently spall off continuously and gradually as oxidation cycles cumulate. Spallation kinetics, possibly established within the very first cycles, is much more progressive than for EB-PVD TBCs characterized by sharp and sudden degradation. For no pre-oxidised and no reinforced sol-gel TBC, the overall life is generally shorter than for the EB-PVD counterpart.

To evaluate the combined effect of the three proposed ways of optimization, namely the pre-oxidation, the use of appropriate heat treatment parameters and the filling of cracks by spray coating, an optimized sol-gel TBC was cyclically oxidized together with an EB-PVD TBC for comparison.

Fig. 11 shows several photographs obtained on both specimens before oxidation and after 500, 1050 and 1480 one-hour cycles at $1100{ }^{\circ} \mathrm{C}$. At the initial state, before oxidation, differences between the sol-gel and the EBPVD TBCs surface morphologies are clearly evidenced. Despite the additional filling brought by spray coating, a crack network outlined by adjacent homogeneous cells still delineates the whole sol-gel TBC outer surface, while the EB-PVD TBC shows a smooth, slightly rough surface.

Following 500th then 1050th one-hour cycle, both samples remain essentially undamaged. Note however that a grazing lighting of the sol-gel TBC highlights a small circular blister, besides initially present before cyclic oxidation. Upon cycling, the blister further develops slightly. Damage mechanisms are significantly different for EB-PVD TBC systems. Indeed, in the case of EB-PVD TBCs, few small cracks initiate on the edge of the specimen sample as shown in Fig. 10f. Finally, after 1480 cycles, failure of the EB-PVD TBC occurs through the extensive propagation of this initial crack. For the sol-gel TBC, even though the blister remains unchanged, spallation of a few individual cells is observed over thick edges indicating probably the onset for the sol-gel TBC degradation. Nevertheless, the optimized reinforced sol-gel TBC shows promising behaviour, exhibiting high durability very similar to that of an EB-PVD TBC.

SEM micrographs of the cross section of the two specimens are presented in Fig. 12. In sol-gel TBC, defects within the YSZ layer - which is adherent to the TGO - as well as rumpling of the bond coat/TGO are observed. In turn, degradation of the EB-PVD TBC is mainly characterized by a delamination at the bond coat/TGO interface, also associated to some 
rumpling. Besides, the higher TGO thickness exhibited by the EB-PVD TBC, suggests that the establishment of higher growth stress and strain during cyclic oxidation might be one of the reasons of the variation in terms of lifetime and failure mechanisms between optimized sol-gel and EB-PVD TBCs. Indeed, although the TGO layer is generally thin as compared to the TBC scale, it may develop high stresses within the system as a consequence of significant thermal expansion mismatch between the TGO and the bond coat. So, failure in EB-PVD TBC mainly originates at the bond coat/TGO interface.

Note that it would be worth to analyze further the rumpling mechanisms to investigate precisely in which system it occurs most extensively as it is reported to be potentially a relevant mechanism contributing to failure. ${ }^{31,32}$

So, the comparison of the sol-gel TBC and EBPVD TBC overall performances during cyclic oxidation, revealed, for both system a comparable lifetime, characterized by almost no noticeable damages even after the 1500th oxidation cycle. These encouraging results point out that pre-oxidation associated to the use of appropriate heat treatment parameters as well as the filling of cracks by spray coating significantly improve the thermo-mechanical performances of sol-gel TBCs.

\section{Conclusions}

Extending cyclic oxidation life of sol-gel TBCs, showing an interesting compromise between thermal insulation and mechanical strength performance, requires to conduct perfectly the various successive steps for processing the YSZ top coat. Beyond the initial dip-coating and controlled withdrawing of the NiPtAl coated super alloy substrates from a slurry composed of the starting sol and previously dried YSZ powder, it is of outmost concern to carry out and control:

i) A pre-oxidation of the NiPtAl bond coat deposited on the substrate to enhance the beneficial diffusion barrier effect.

ii) A sintering heat treatment that develops a regular in-plane crack network within the TBC as it gets denser.

iii) A reinforcement of the TBC by partially filling those cracks using sol-gel spray-coating.

Using both XRD synchrotron radiation and cyclic oxidation test, the performances of sol-gel TBCs in terms of microstructural evolution, mechanical response to high temperature exposure and durability upon sintering and both early and long-term oxidation cycles are investigated. The in situ monitoring of the strain within the sol-gel TBC during post deposition heat treatment reveals the occurrence of various successive mechanisms including - as the temperature is increased from room temperature to $1100{ }^{\circ} \mathrm{C}$ - the calcination of organic compounds, the constrained thermal expansion, the volume reduction of the $\mathrm{Al}_{2} \mathrm{O}_{3}$ TGO resulting from the $\theta$ to $\alpha$ transition and to a lower extent to the TGO growth, the sintering-induced densification and the initiation and growth of the crack network. Residual strain remains in the TBC after completion of sintering and the very first oxidation cycle further enhance this strain, through various effect such as creep of the bond coat, thickening of the TGO and mismatch in coefficient of thermal expansion between the bond coat and the barrier.

Pre-oxidation of sol-gel TBC drastically extend cyclic oxidation life as the initial $\mathrm{Al}_{2} \mathrm{O}_{3}$ TGO limits the growth kinetics of the scale thus reducing the depletion of the $\mathrm{Al}$ reservoir in the bond coat and decreasing the stress associated with the TGO development. Finally, optimized sol-gel TBCs including pre-oxidation and spray-coating reinforcement are shown to present cyclic oxidation life very similar to standard state-of-the-art EB-PVD TBC.

Further development of the work may focus on the investigation of the strain evolution within reinforced sol-gel TBCs as well as of the monitoring of the crack initiation and propagation using XRD tomography.

\section{Acknowledgment}

The authors acknowledge the European Synchrotron Radiation Facility (ESRF) for beam time on ID15B and, particularly, V. Honkimäkiand T. Buslaps for their help and useful discussions.

\section{References}

1. Padture N, Gell M, Jordan EH. Thermal barrier coatings for gas-turbine engine applications. Science 2002;296:280-4.

2. Goswami B, Ray Ashok K, Sahay SK. Thermal barrier coating system for gas turbine application - a review. High Temp Mater Processes 2004;23:73-92.

3. Evans AG, Mumm DR, Hutchinson JW, Meier GH, Pettit FS. Mechanisms controlling the durability of thermal barrier coatings. Prog Mater Sci 2001;46:505-53.

4. Wang X, Lan WH, Xiao P. Fabrication of yttria stabilized zirconia coatings by a novel slurry method. Thin Solid Films 2006;494:263-7

5. Ren C, He YD, Wang DR. Cyclic oxidation behavior and thermal barrier effect of YSZ- $\left(\mathrm{Al}_{2} \mathrm{O}_{3} / \mathrm{YAG}\right)$ double-layer TBCs prepared by the composite sol-gel method. Surf Coat Technol 2011;206:1461-8.

6. Viazzi C, Bonino JP, Ansart F. Synthesis by sol-gel route and characterization of yttria stabilized zirconia coatings for thermal barrier applications. Surf Coat Technol 2006;201:3889-93.

7. Sniezewski J, Le Maoult Y, Lours P, Pin L, Minvie Bekale V, Monceau D, Oquab D, Fenech J, Ansart F, Bonino J-P. Sol-gel thermal barrier coatings: optimization of the manufacturing route and durability under cyclic oxidation. Surf Coat Technol 2010;205:1256-61.

8. Pin L, Ansart F, Bonino J-P, Maoult YL, Vidal V, Lours P. Processing, repairing and cyclic oxidation behaviour of sol-gel thermal barrier coatings. Surf Coat Technol 2011;206:1609-14.

9. Pin L, Ansart F, Bonino J-P, Le Maoult Y, Vidal V, Lours P. Reinforced sol-gel thermal barrier coatings and their cyclic oxidation life. J Eur Ceram Soc 2013;33:269-76.

10. Garriga-Majo DP, Shollock BA, Mc Pahil DS, Chater RJ, Walker JF. Novel strategies for evaluating the degradation of protective coatings on superalloys. Int J Inorg Mater 1999;1:325-36.

11. T.E. Strangman, Columnar grain ceramic thermal barrier coatings, Brevet US patent 4321311 (1982)

12. Tolpygo VK, Clarke DR. The effect of oxidation pre-treatment on the cyclic life of EB-PVD thermal barrier coatings with platinum-aluminide bond coats. Surf Coat Technol 2005;200:1276.

13. Strauss D, Müller G, Schumacher G, Engelko V, Stamm W, Clemens D, Q WJ. Oxide scale growth on MCrAlY bond coatings after pulsed electron beam treatment and deposition of EBPVD-TBC. Surf Coat Technol $2001 ; \mathbf{1 3 5}: 196$.

14. Bruneseaux F, Aeby-Gautier E, Geandier G, Da Costa Teixeira J, Appolaire B, Weisbecker P, Mauro A. In situ characterizations of phase transformations 
kinetics in the Ti17 titanium alloy by electrical resistivity and high temperature synchrotron X-ray diffraction. Mater Sci Eng A 2008;476:60-8.

15. Muzzi L, Corato V, della Corte A, De Marzi G, Spina T, Daniels J, Di Michiel M, Buta F, Mondonico G, Seeber B, Flükiger R, Senatore C. Direct observation of $\mathrm{Nb}_{3} \mathrm{Sn}$ lattice deformation by high-energy X-ray diffraction in internal-tin wires subject to mechanical loads at $4.2 \mathrm{~K}$. Supercond $S c i$ Technol 2012;25(5):054006.

16. Steuwer A, Daniels JE. In-situ stress and strain measurements around cracks using synchrotron X-ray diffraction. J Strain Anal Eng Des 2011;46(7):593-606.

17. Pyzalla A, Reetz B, Jacques A, Feiereisen JP, Ferry O, Buslaps T. Synchrotron radiation in-situ analyses of $\mathrm{AA} 6061+\mathrm{Al}_{2} \mathrm{O}_{3}$ during tensile deformation at ambient and elevated temperature. In: Recent advances in experimental mechanics. Netherlands: Springer; 2004. p. 527-34.

18. Mittemeijer EJ, Welzel U. The "state of the art" of the diffraction analysis of crystallite size and lattice strain. Z Kristall - Crystalline Materials 2008;223:552-60.

19. Fenech J. Nouvelles compositions de revêtements de zircone substituée (Y, La, Sm, Er) élaborés par la voie sol-gel: application aux barrières thermiques multicouches. Ph.D. thesis, University of Toulouse; 2010. p. 105-7.

20. Viazzi C. Elaboration par le procédé sol-gel de revêtements de zircone yttriée sur substrats métalliques pour l'application barrière thermique. Ph.D. thesis, University of Toulouse; 2007.

21. Popma RLW. Sintering characteristics of nano-ceramic coatings. Ph.D. Thesis, University of Groningen; 2002.

22. Specht ED, Tortorelli PF, Zschack P. In situ measurement of growth stress in alumina scale. Powder Diffr 2004;19:69-73.
23. Hou PY, Paulikas AP, Veal BW. Growth strains and stress relaxation in alumina scales during high temperature oxidation. In: 6th Symposium on High Temp. Corr. and Protection of Materials. 2004.

24. Schumann E, Sarioglu C, Blachere JR, Pettit FS, Meier GH. Hightemperature stress measurements during the oxidation of NiAl. Oxid Met 2000;53:259-72.

25. Calata JN. Densification behavior of ceramic and crystallizable glass materials constrained on a rigid substrate. Ph. D. Thesis, Virginia Polytechnic Institute and State University; 2005.

26. Pan D, Chen MW, Wright PK, Hemker KJ. Evolution of a diffusion aluminide bond coat for thermal barrier coatings during thermal cycling. Acta Mater 2003;51:2205-17.

27. Rösler J, Baker M, Volgmann M. Stress state and failure mechanisms of thermal barrier coatings: role of creep in thermally grown oxide. Acta Mater 2001;49:3659-70

28. Cavaletti E. Etude et développement de barrière de diffusion pour les souscouches de système barrière thermique. Ph.D. thesis, University of Toulouse; 2009.

29. Vialias N. Etude de la détérioration par oxydation haute température et interdiffusion de systèmes revêtement/superalliage à base de Nickel-Prévision de durée de vie. Ph.D. thesis, University of Toulouse; 2004.

30. Tolpygo VK, Clarke DR. On the rumpling mechanism in nickel-aluminide coatings Part I: an experimental assessment. Acta Mater 2004;52: 5115-27.

31. Tolpygo VK, Clarke DR. Morphological evolution of thermal barrier coatings induced by cyclic oxidation. Surf Coat Technol 2003;163164:81-6.

32. Tolpygo VK, Clarke DR. Surface rumpling of a (Ni, Pt)Al bond coat induced by cyclic oxidation. Acta Mater 2000;48:3283-93. 